\title{
How to grow a city: cultivating an urban agriculture action plan through concept mapping
}

Wanda Martin ${ }^{*}$ (D) and Lindsey Wagner ${ }^{2}$

\begin{abstract}
Background: Urban agriculture is a means to improve community health and reduce health inequities. It encourages civic participation in food system governance and offers citizens opportunities to explore concepts of food sovereignty within an urban setting. The objective of this study was to engage civic participation in developing an urban agriculture action plan for a Canadian prairie city. The purpose was to identify the short- and long-term goals and the barriers and facilitators to growing more food in the city.

Results: Using a combination of Concept Systems ${ }^{\mathrm{TM}}$ concept mapping and group discussions, 66 participants contributed to developing a plan to advance urban agriculture. Six concepts form the action plan. Growing more food within public spaces in order to make urban agriculture more visible and improving education strategies are two areas that participants ranked both important and feasible. Participants relayed that increased visibility could create a cultural shift to strengthen the local food knowledge.

Conclusions: School engagement, community development, maximizing food production in public places, and attending to regulations and bylaws are focus areas for improving urban agriculture. An integrated vision from the city administration with a paid position to make connections, oversee bylaws, and consider local food procurement systems is necessary to advance a healthy community-based food system. A systems approach to building a resilient food system and strengthening food sovereignty will require political will and a public mandate.
\end{abstract}

Keywords: Urban agriculture, Civic participation, Food security, Food sovereignty, Community health

\section{Background}

Experts anticipate there will be five billion people living in urban settings by the year 2025, and are questioning our ability to meet the demand for nutritious food [1]. Many North American cities have obesogenic built environments that allow for access to low-quality, energydense food and little opportunity for active living [2]. This is particularly evident in lower-income neighborhoods and results in growing health inequities [2]. Dixon et al. [3] link health inequities to a number of structural changes to the global food supply since the 1970s that have resulted in the consumption of more processed

\footnotetext{
*Correspondence: wanda.martin@usask.ca

${ }^{1}$ College of Nursing, University of Saskatchewan, 104 Clinic Place, Saskatoon, SK S7N 2Z4, Canada

Full list of author information is available at the end of the article
}

food and simple carbohydrates, and fewer vegetables and fruits. The question then is how to change the structure to improve the uptake of healthy foods such as vegetables and fruits. The purpose of this paper is to describe how to operationalize urban agriculture, thereby improving community health and reducing health inequities.

Urban agriculture has many forms and is often part of the role of municipal planning departments [4]. Urban agriculture encompasses gardening in backyards, schools, public right-of-way and boulevards; community gardens; urban farms; rooftop and balcony gardens; hydroponic, aquaculture, and vertical gardening; keeping microlivestock such as hens, rabbits, and bees; greenhouses; permaculture design in parks; edible landscaping; public orchards or food forests; and agricultural parks [5, 6]. Increasingly, cities in North America are encouraging 
urban agriculture and developing municipal food strategies [7]. For example, in 2015, Sacramento City Council approved two ordinances related to urban farming, allowing residents to grow and sell food directly from their property, and giving these urban farmers a tax incentive in the process [8]. Cities such as Detroit and Los Angeles have focused specifically on improving urban food production in disadvantaged areas with high-needs clients and are examples of urban agriculture programs that can advance health equity [9]. In Canada, there are a number of cities, including Vancouver, Edmonton, and Toronto, with food policy commitments that include urban agriculture yet action on the commitments varies across settings $[7,10]$.

Public engagement is an important aspect to a healthy and just society [11]. Urban agriculture activities encourage public participation in food system governance and offer citizens opportunities to explore concepts of food sovereignty within an urban setting. Food sovereignty refers to a process of expanding democracy to regenerate local, autonomous, healthy, and ecologically sound food systems that respect the rights of people to decent working conditions and incomes [12,13]. A people-centered approach allows for food justice and food sovereignty where context-specific needs can be addressed [14]. The food sovereignty movement recognizes political and economic power in the food system and is a critical alternative to the neoliberal model favoring market forces over health and health equity [15]. Weiler et al. [16] describe how food sovereignty and health equity share the goal to promote human thriving by equalizing access to power and improving the flow of goods through the food system. Urban agriculture provides opportunities for citizens to participate directly in their food system, while gaining a sense of power and control that can improve health. Furthermore, Sommers and Smit [17] describe urban agriculture as a means for cultural preservation and crime prevention, to name but a few of the key areas that contribute to public engagement in urban settings. This paper reports on a study designed for public engagement in developing an urban agriculture action plan for a Canadian prairie city. Surrounded by large farms of oilseed, grains, pulses, and cattle, Saskatoon, Saskatchewan, has great food-growing potential. In contrast to its large export industry, the province only produces seven percent of the in-season self-sufficiency needs of Saskatchewan people [18]. With this food production gap in mind, there is an opportunity to enhance civic operations and change the urban built environment in a manner that will contribute to a community-based food system, build resilience against an unpredictable climate future, and benefit the local population through greater vegetable and fruit production. Implementing a sustainable urban agriculture action plan requires practical planning in order to be successful [19]. Though there is ample literature citing the benefits of increased urban agriculture [4, $7,17,20,21]$, there is a gap in the research when it comes to the steps required to execute a comprehensive, citywide strategy $[5,19]$. We intended this study to address this gap. The action plan is available to municipal government leaders to guide changes to the built environment, promoting access to high-quality food, active living, and economic development. This will not only benefit the City of Saskatoon, but also other similar municipalities looking to enhance their citizen's health through the expansion of urban agriculture.

\section{Methods}

This study had two main objectives: (1) to create an urban agriculture action plan that can increase access to quality affordable food and opportunities for physical activity and (2) to identify barriers and propose solutions to increased support for urban agriculture. Given the wide range of players involved in this potential public health intervention, we used a systems thinking approach. Systems thinking is useful because it considers both the larger, holistic picture, while also allowing the problem to be reduced to variables that can be measured and analyzed in an empirical manner [22]. In line with this theoretical approach, we used Concept Systems ${ }^{\mathrm{TM}}$ concept mapping as our main method of data collection and analysis. We used the concept mapping approach outlined by Trochim [23] to provide structure to our data generation, sorting, and rating process. We also supplemented data from this exercise with group discussions.

For the data generation (brainstorming) phase of the project, we created an online response systems for participants to complete the statement, "A way to grow more food in Saskatoon is.... We circulated the web link in three ways: through a shareable Facebook post, to all of Saskatoon's community associations and asked them to share the link with their membership, and through contacts in the City of Saskatoon. Thirty-three respondents generated 58 unique statements in the brainstorming phase.

For the data sorting and rating phase, we held ten community meetings across the city with participants recruited through the same means as the brainstorming phase. Additionally, we placed posters advertising these meetings in the community centers and libraries where they were hosted at least a week before the meeting took place. The participants completed three questionnaires: a demographics questionnaire, a questionnaire in which the participants rated each of the 58 statements based on importance, and a questionnaire in which the participants rated each of the 58 statements 
based on feasibility. The demographics questionnaire was included to allow us to understand the heterogeneity of our data set. After completion of the questionnaires, we instructed participants to sort the statements into distinct groupings or concepts.

We analyzed the data using Concept Systems ${ }^{\mathrm{TM}}$ software. This software converts the information from sorting statements into a similarity matrix, with the statements plotted on a point map using non-metric multidimensional scaling (MDS) [24]. MDS was applied in two dimensions in order to produce $X, Y$ coordinates suitable for representation on a two-dimensional surface. If more participants placed statements in the same grouping, they appear closer together on the point map. Based on the point map, hierarchical cluster analysis allowed for creating statement clusters. This partitions the point map into non-overlapping clusters in two-dimensional space. We decided on the number of clusters by starting with a large number of clusters (15) and then reducing the number of clusters each time asking whether all the statements made sense grouped together, or whether they would make better sense if separated. We continued reducing the number of clusters until we felt each cluster formed distinct concepts. Figure 1 shows the cluster map, which is based on the point map.
In addition to the concept mapping exercise, group participants were lead through a semi-structured discussion on how to grow more food in Saskatoon. We had 66 participants across the ten sites in the group discussions. We audio-recorded the discussions for ease of note taking, analyzing them with support of NVivo 11 as a means to code ideas and to elicit recurring themes. The information from this exercise augmented the concept mapping data.

\section{Compliance with ethical standards}

As the study involved human participants, we obtained ethical approval from the University of Saskatchewan Research Ethics Board (BHE\#16-87). We informed all participants of the risks/benefits and obtained a signed informed consent form from each person.

\section{Results}

There were 55 people who completed the demographics questionnaire and the sorting and rating forms. Most respondents lived in a single-family dwelling and had at least some experience growing food in the city (see Table 1). Most participants also indicated they were food secure and had adequate income to meet their needs.

The six clusters in the concept map are public education, public spaces, community development, schools,

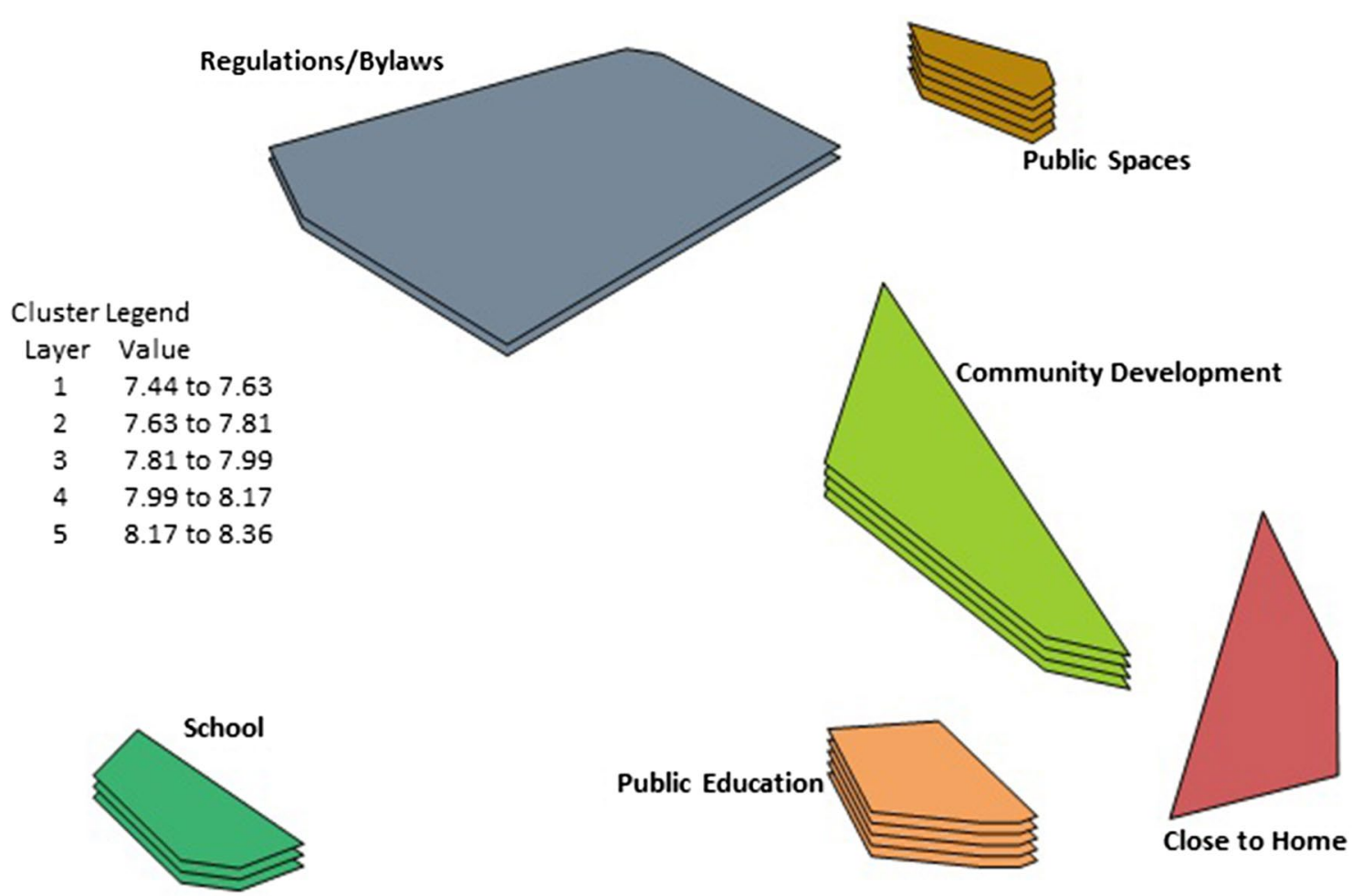

Fig. 1 Cluster map stratified by average importance 
Table 1 Demographics

\begin{tabular}{|c|c|c|}
\hline Age & Range 22-73, median 38 & \\
\hline \multirow[t]{3}{*}{ Gender } & Male & $13(24 \%)$ \\
\hline & Female & $41(75 \%)$ \\
\hline & I do not want to respond & $1(2 \%)$ \\
\hline \multirow[t]{2}{*}{ Income meets needs } & Yes & $47(85 \%)$ \\
\hline & Not always & $8(15 \%)$ \\
\hline \multirow[t]{3}{*}{ Experience gardening } & Some-I grew up on a farm but have never grown food in the city & $1(2 \%)$ \\
\hline & A bit—l am new to gardening & $18(33 \%)$ \\
\hline & A lot-I regularly have a vegetable garden & $36(65 \%)$ \\
\hline \multirow[t]{3}{*}{ Food security—in past month } & We have always had enough & $47(85 \%)$ \\
\hline & We have always had enough, but not the best kind & $7(13 \%)$ \\
\hline & Sometimes we did not have enough for everyone in our household & $1(2 \%)$ \\
\hline \multirow[t]{6}{*}{ Type of housing } & Apartment & $1(2 \%)$ \\
\hline & Condominium & $4(7 \%)$ \\
\hline & Townhouse & $1(2 \%)$ \\
\hline & Duplex & $1(2 \%)$ \\
\hline & Single-family dwelling & $46(84 \%)$ \\
\hline & Other & $2(3 \%)$ \\
\hline
\end{tabular}

regulations and bylaws, and close to home. Figure 1 depicts the two-dimensional cluster map of all of the submitted statements, with statements sorted together more frequently being placed closer together on the map. We have added a third dimension to the cluster map in the form of layers. The layers in the cluster map represent which clusters are more important. Participants scored each statement individually for how important participants felt it was to be in the action plan; this resulted in calculating an average score for importance for each cluster of statements. A greater number of layers indicate a higher score of how important each cluster was. We have similar data for feasibility. Below we provide a brief description of each cluster.

\section{Public education}

Overall, concepts falling under the heading of "Public Education" were rated as both the most important and the most feasible for an urban agriculture action plan. Actionable items included things such as public education campaigns on urban agriculture and providing public training on different types of urban agriculture and edible native plants. Also included within the concept was the recommendation to "Make it culturally acceptable to grow food." Participants felt it was necessary not only to provide the information on how to grow food, but also to create a cultural shift. This was a recurring theme within the group discussions. One participant stated, "We need to realize that our food in the grocery store is coming from the ground beneath our feet." Another participant acknowledged that most people do not know where their food comes from, and identified this as a serious problem. Participants seemed to think that this disconnect from the food system stemmed from the modern industrial food system where food is highly processed and packaged in Styrofoam and plastic [25]. Another person cited a "generational gap" that now exists when it comes to the knowledge of how to garden, and emphasized that people do not know where to begin. This knowledge deficit also extends to cooking and preserving food.

\section{Public spaces}

This cluster was the second most important cluster overall. Ideas from this cluster included growing food in public parks, such as berry orchards or creating "urban food forests," which participants described as park with all food-bearing plants consisting of nut trees, fruits, and berries. Other actionable ideas included using public spaces, such as boulevards and vacant lots, for growing food, and planting edible plants along public walking paths. During discussions, participants raised multiple benefits of using public spaces for community gardens in particular. This included the expense of individual yard conversions, the challenges of working around fences and buildings in private yards to find good growing conditions, social opportunities through gardening in public spaces, and gardening spaces for people living in highdensity housing. Additionally, participant considered the value of community gardens as a place for learning and knowledge sharing as an asset when trying to combat the knowledge deficit described in "Public Education" discussions above. In general, the downsides to gardening in 
public spaces revolved around Saskatoon-specific bylaws around fencing and selling produce. City-sponsored community gardens are not allowed fencing, which participants expressed as necessary to discourage vandalism. Selling produce from community gardens is also not allowed.

\section{Community development}

Community development cluster included statements about bringing people together, building connections, and bridging available resources with the people who need them. Actionable items included connecting wouldbe gardeners with unused gardening space, including links to local urban agriculture organizations on the city Web site, creating city-supported resources to help citizens begin urban agriculture projects, and expanding backyard gardening programs. Participants identified the need for a community calendar that lists all current gardening events/workshops. To ensure this information reaches a broader audience, community radio stations could be involved so that all citizens are connected. The idea of using gardening to connect with seniors and to ensure seniors are included in the community came up multiple times. Along with this, participants discussed the benefits of shared gardens with seniors. Having gardens near seniors' residences can provide the seniors with both the opportunity to be engaged socially with other community members and an outlet where they can share their gardening knowledge even if they may not have the physical ability to do much of the manual labor.

\section{Schools}

In the concept mapping exercise, three different points came across as being particularly important concerning promoting food in schools: (1) promoting the creation of gardening programs within schools, (2) having school cooking projects, and (3) connecting schools with local community associations to find space for outdoor classrooms. The statements were echoed in the group discussions, where incorporating gardening into the school system was very well received. Participants referred to gardening in schools as not only an educational endeavor, but also a "cultural thing." Even though participants considered this cluster to be quite important, they also considered it to be of particularly low feasibility. In the discussions, participants drew attention to multiple ways in which incorporating gardening into schools would be logistically challenging: Teachers are consistently short on time, so asking them to prepare another subject may not be realistic; gardening projects may require additional funding for the schools, which can be hard to attain; and gardens require summer maintenance when schools are closed. There were accounts of successful programs at a number of schools, however, such as a "Grow and Home" program where the students commit to helping take care of the garden beds during the summer. Students participating in practical and applied arts classes had built much of the infrastructure for existing school gardens with the "Grow and Home" program. This coordination between classes made the gardening program more feasible and cost-effective, since students require materials for all shop projects. The use of the gardening program would then make the arts class materials an investment that benefits the school and its students for years to come.

Participants also suggested that school gardens could be a place for teaching English as an additional language. Having hands on gardening experience would be an engaging environment to learn the language while also allowing new Canadians to grow food familiar to their home country. Lastly, the university could also be involved through horticultural or teaching internships.

\section{Regulations/bylaws}

Participants identified city bylaws that planners could consider when forming new suburbs and adjusting existing city plans. Actionable items included making sure that community gardens/areas for urban agriculture are incorporated into new community plans (specifically ensuring that these areas have access to water for irrigation), repurposing unused city land for growing food, and creating more community gardens specifically near high-density housing. Suggestions of notable feasibility and importance also included incorporating edible landscaping into the official community plans and decreasing penalties for owners of vacant lots if they allow food to be grown on them. The primary recommendation in this concept was to "create city bylaws and policies to support and encourage urban agriculture." Participants identified problematic bylaws during the group discussions, such as the ban on putting up a fence around community gardens or planting/installing anything the city would considered permanent. This is banned because the city renews the gardens' "lease" on the area year to year, meaning that permanent plants or structures would be more costly to move or destroy. Participants did note, however, that community gardens are already under contract to return the land to its original state if the garden disbands. Though this would be harder with larger, permanent plants, participants felt that the benefits of the additional produce and increased personal investment of the gardeners should be a consideration.

\section{Close to home}

Participants generally emphasized that having a place to garden close to home was "key" during the group 
discussions. However, the discussion would often turn toward public spaces near people's homes as opposed to areas on their own property such as backyards, front yards, or alleyways. Thus, focusing on public spaces within individual neighborhoods seems to be the better strategy for increasing urban food production. Data reflect this in the concept map in that the "Close to home" concept was the least important concept and participants rated "Public spaces" as one of the most important concepts. The three actionable items from this concept included promoting the use of front lawns as gardening space, a possible "Grow food, not lawns" campaign to encourage people to convert existing lawns, and promoting cooperative food-growing organizations.

One notable discussion under this concept was whether or not it was a good idea for families with children to garden in their backyards. One participant was concerned about taking up the kids play space within the yard if she decided to convert her yard to gardening space, but another participant noted that gardening was a good opportunity to involve children and to educate them. This issue of not having enough space for both activities of gardening and play was raised by other participants, but some emphasized that you can grow a surprising amount of food in a small area if you garden intensively.

\section{Other endeavors}

When talking about urban agriculture with participants, the discussion inevitably intertwined with the issues of sustainability, environmental health, water, food security, and ecological responsibility. Topics included lowering pesticide use within the city, ensuring water runoff can be soaked up by the ground instead of just diverted into the sewer system, and ensuring the use of climateadjusted plants along with a diversity of species to protect against single species disease devastating an entire crop. Participants seemed genuinely concerned with broader environmental issues and their interactions with how we manage our food systems. Though these items do not fall directly into the scope of an urban agriculture plan, we are encouraged to keep a holistic idea of health when deciding the best path forward. This includes the concept that human health is tied directly to the health of the surrounding environment.

\section{Discussion}

The purpose of this study was to inform changes to urban planning, including the built environment to promote access to high-quality food and active living that can contribute to improved health and community resilience. The successful implementation of an urban agriculture action plan depends on political will and having a viable ecosystem with sufficient land for cultivation and appropriate knowledge on how to grow food [26]. Saskatoon has an appetite to improve urban food production as demonstrated through the Vacant Lot Garden Incentive implemented in 2016 [27], but lack commitment of a municipally funded staff person or food policy council. A combination of municipal leadership, appropriate regulations and bylaws, and engaged citizens will be necessary to move this work forward. The concept map and rating system allow for a strategic approach to action based on local knowledge and conditions. The process of civic engagement with the Concept Systems ${ }^{\mathrm{TM}}$ methodology was an essential part of working with the community to develop community-based solutions.

Not untypical of many public health interventions, public education was considered the most feasible and important approach to growing more food in the city. Though many consider education the best way to improve public health, it is not always the most effective [28]. Changing the context and improving socioeconomic factors has a much greater effect than counseling and education [28]. The participants in this study had working knowledge of how to grow food, but they expressed that most other people had lost this knowledge through the generations. A subsequent randomly dialed telephone survey of a representative sample in Saskatoon identified that $50.2 \%$ of people in the city had planted a food garden in the previous 12 months [29]. This suggests that many people do know how to grow food, but there is a perception of low agricultural literacy. This may be because growing food is not in the public eye but often occurs behind fenced yards. If urban agriculture were more public, it could help to "normalize" local food production, which is necessary to create a cultural shift from an import-dependent city to a place where it is seen as commonplace to grow your own food.

Growing food in public spaces will contribute to that culture shift. Barthel et al. [26] argue that people in many cities are losing their knowledge related to agriculture, but such knowledge can be restored through community gardens, which have served as a major source of resilience in times when food was scarce. Participants in our study advocated for municipal government to reallocate underutilized public spaces toward growing food, whether through the development of community gardens, allotment gardens, or more permanent fruit-bearing trees/ bushes that would be available for public consumption.

Furthermore, participants noted the public exchange of knowledge as an important aspect of growing food in public spaces. Wang and Glicksman [30] found this to be especially important for low-income seniors who enjoyed connecting with others, and were interested in continuing a past tradition of growing their own food. 
Community development occurs through sharing knowledge and helping each other. Seniors who are still in their own homes could possibly benefit from a sharing backyard gardening program where they have the opportunity to share their time, wisdom, and gardening space with those who may appreciate some help.

Working with schoolchildren as an investment in securing local knowledge of food production is an extension of the earlier concepts of public education, growing in public spaces, and community development. Relying on teachers to integrate food knowledge requires careful planning with good supports and adequate resources. There are a number of agriculture-type programs operating in schools in Canada, such as Agriculture in the Classroom and Farm to School. While such programs have been operating throughout North America for some time, there is a need to examine such programs for effectiveness [31]. Powell and Wittman [32] describe the importance of farm to school programs as structural mechanisms to reshape local food systems and to support goals of food sovereignty. For schools truly to be a driver to support a resilient and healthy food system, they need to be engaged in local food procurement as well as teaching food and agriculture literacy.

A systems approach is necessary to using urban agriculture as a means for creating livelihood strategies to improve health equity. Participants noted there were many different small projects, but there was a lack of an "integrated vision" or a "mainstream authority" to advancing a healthy local food system. Such an authority could come from the municipal government as a paid position that could oversee regulations and bylaws, local food procurement systems, and connecting people either looking to learn how to garden or looking for help when seeking gardening resources. Establishing a paid city staff position would allow for long-term continuity, instead of relying only on non-profits (who often lack consistent and reliable funding) or on volunteers who may be prone to burn out, and would allow implementation of an urban agriculture action plan in a sustainable manner.

Urban agriculture in the Canadian setting is not likely to improve food security unless there is easy and free access with adequate supports to provide people with the tools and knowledge necessary to grow food. In fact, urban agriculture can deepen social and health inequities because it is the propertied class with time who benefit the most with this activity [33]. As demonstrated by our participants, it is the middle class who most often will participate in urban agriculture activities. Saskatoon is fortunate that there are committed organizations that work to overcome such a barrier, but it should not be overlooked that middle-class homeowners can be at an advantage in this area. As such, a city paid staff position would need to have a clear mandate on the scope of the work as to contribute to a reduction in food insecurity, or working with homeowners to increase urban food production and build overall community resilience and food sovereignty.

There were a number of limitations to this study. First, Saskatoon is a unique site for advancing urban agriculture. As an agriculture export province, many urban people have farm experience, but this does not translate to widespread successful small-scale urban vegetable production. There are, however, retired farmers who are interested in mentoring home gardeners and remaining active in the agriculture community. Second, the majority of our participants were Caucasian, middle-class, and educated homeowners who were interested in advancing urban agriculture. This narrow demographic was largely due to the recruitment method through community associations, but also in the lack of incentives offered to participate. People with childcare or transportation needs would be less likely to attend public meetings without some financial assistance. As a city with a thriving Indigenous community, there is a growing interest in gardening and Indigenous food sovereignty [34], yet this population was underrepresented in our study. Third, Saskatoon is lacking a municipal food policy council. While there is a food policy council, there is not a formal link with the City of Saskatoon. Not unlike Edmonton, Alberta, there is a demand for a community-based food system in Saskatoon. Edmonton, however, recognized a need for a comprehensive cross-sectoral food strategy so used a citizen-engaged process with the municipal government to develop a food and urban agriculture strategy [10]. The strategy comes with one full-time staff person to work on implementation, which would be essential for Saskatoon's plan to gain traction. Working with the process currently in place, the findings from this action plan remain with the city planners and the Saskatoon Food Council but will only be taken up on a voluntary basis.

\section{Conclusions}

Urban agriculture is one way to promote sustainable livelihoods and improving health equity [16]. If a city has appropriate financial and physical supports, and a willing citizenry, urban agriculture is an actionable way to promote food sovereignty and improve quality of life. The concept map produced in this study is a framework that other municipalities can apply. It is important, however, to match an action plan to the local context.

The strength of this study is in the civic engagement to develop the action plan. The limitations, however, are in the challenges of taking action at the system level. However, as Frieden [28] noted, system-level change generally results in a greater overall impact than relying on 
individual education-based interventions, so the extra challenge of such a broad intervention is worth the effort.

The three most important areas to focus on will be public education to address the "knowledge gap" that exists between the older and younger generations, utilizing public spaces to make gardening both accessible and visible, and community development to connect people to each other and to gardening resources. Additionally, by working on these practical steps, it will also work toward the cultural shift that will be required to make this movement sustainable into the future.

As it was eloquently phrased by one of the participants, "We're absolutely dependent on the oxygen, and the air, and the earth, and the six inches of topsoil, but we don't see that every day, and we start to live very disconnected." By normalizing urban agriculture, and making it more visible, we can work toward bridging this disconnect from our food system and our environment and allow us to reap all of the health benefits that increased urban agriculture has to offer. Reconnecting our population with the food system and establishing food sovereignty will take time, but it is an achievable goal.

\section{Authors' contributions}

WM conceived the study and wrote the proposal, collected data, did the majority of the analysis, and wrote the initial research report. LW organized data collection meetings and participated in data collection and analysis. LW revised the research report for publication. Both authors edited and revised the publication version. Both authors read and approved the final manuscript.

\section{Authors' information}

WM is a pre-tenured assistant professor establishing a program of research. LW is both a nursing undergraduate student and a master's student in Community Health and Epidemiology at the University of Saskatchewan. She has been the research assistant on this project.

\section{Author details}

${ }^{1}$ College of Nursing, University of Saskatchewan, 104 Clinic Place, Saskatoon, SK S7N 2Z4, Canada. ${ }^{2}$ Department of Community Health and Epidemiology, University of Saskatchewan, Box 7, Health Science Building, 107 Wiggins Road, Saskatoon, SK S7N 5E5, Canada.

\section{Acknowledgements}

We would like to thank the Saskatchewan Health Research Foundation for the funding required to do this study. We would also like to thank Gord Ens with the Saskatoon Food Council for his support throughout the project and Latraca and London Lesko for their help in preparing the materials for the community meetings.

\section{Competing interests}

The authors declare that they have no competing interests.

\section{Availability of data and materials}

Not applicable.

\section{Consent for publication}

Not applicable.

\section{Ethics approval and consent to participate}

As the study involved human participants, we obtained ethical approval from the University of Saskatchewan Research Ethics Board (BHE\#16-87). All participants were made aware of the risks/benefits and signed an informed consent form.

\section{Funding}

This research was funded by the Saskatchewan Health Research Foundation. The funding body did not have any role in the study design, data collection, analysis, or interpretation, nor in writing the manuscript.

\section{Publisher's Note}

Springer Nature remains neutral with regard to jurisdictional claims in published maps and institutional affiliations.

Received: 4 October 2017 Accepted: 4 May 2018

Published online: 18 May 2018

\section{References}

1. MacRae R, Gallant E, Patel S, Michalak M, Bunch M, Schaffner S. Could Toronto provide $10 \%$ of its fresh vegetable requirements from within its own boundaries? Matching consumption requirements with growing spaces. J Agric Food Syst Community Dev. 2010;1(2):105-27.

2. Engler-Stringer R, Muhajarine N, Le H, del Canto S, Ridalls T. Characterizing the food environment in Saskatoon for families with children: research methods and descriptive results. Saskatoon: Saskatchewan Population Health and Evaluation Research Unit; 2014.

3. Dixon J, Omwega AM, Friel S, Burns C, Donati K, Carisle R. The health equity dimensions of urban food systems. J Urban Health Bull NY Acad Med. 2007:84(1):i118-29.

4. Pothukuchi K, Kaufman JL. Placing the food system on the urban agenda: the role of municipal institutions in food systems planning. Agric Hum Values. 1999:16(2):213-24.

5. La Rosa D, Barbarossa L, Privitera R, Martinico F. Agriculture and the city: a method for sustainable planning of new forms of agriculture in urban contexts. Land Use Policy. 2014;41:290-303.

6. Smit J, Nasr J. Urban agriculture for sustainable cities: using wastes and idle land and water bodies as resources. Environ Urban. 1992;4(2):141-52.

7. Mansfield B, Mendes W. Municipal food strategies and integrated approaches to urban agriculture: exploring three cases from the global north. Int Plan Stud. 2013;18(1):37-60.

8. Mukherji N. Innovative land use policy empowers citizens to improve health. Zoning Pract. 2010;3(10):1-7.

9. Friel S, Hancock T, Kjellstrom T, McGranahan G, Monge P, Roy J. Urban health inequities and the added pressure of climate change: an actionoriented research agenda. J Urban Health. 2011;88(5):886.

10. Beckie MA, Hanson L, Schrader D. Farms or freeways? Citizen engagement and municipal governance in Edmonton's food and agriculture strategy development. J Agric Food Syst Community Dev. 2016:4(1):15-31.

11. Wharf-Higgins J, Weller F. Influencing policy from the outside: are citizens game changers or sidelined? In: Westhues A, Wharf B, editors. Canadian social policy: issues and perspectives. 5th ed. Waterloo: Wilfrid Laurier University Press; 2012. p. 61-77.

12. Blouin C, Lemay JF, Konforti L, Imai J, Ashraf K. Local food systems and public policy: a review of the literature. Ottawa: Equiterre \& The Centre for Trade Policy and Law, Carleton University; 2009.

13. Pimbert M. Towards food sovereignty: reclaiming autonomous food systems. London: The International Institute for Environment and Development; 2010.

14. Jacobs RC. Understanding neighbourhood food access: practices and perspectives of residents of Scarborough Village, Toronto. Toronto: University of Toronto; 2017

15. Wittman H, Desmarais AA, Wiebe N, editors. Food sovereignty in Canada. Halifax: Fernwood Publishing; 2011

16. Weiler AM, Hergesheimer C, Brisbois B, Wittman H, Yassi A, Spiegel JM. Food sovereignty, food security and health equity: a meta-narrative mapping exercise. Health Policy Plan. 2014;30(8):1078-92.

17. Sommers P, Smit J. Promoting urban agriculture: a strategy framework for planners in North America, Europe, and Asia. Cities feeding people series; rept 9. 1994.

18. Kouri D. Towards a food strategy for Saskatoon: Saskatoon regional food systems assessment and action plan. Saskatoon; 2013. 
19. Thibert J. Making local planning work for urban agriculture in the north american context. J Plan Educ Res. 2012;32(3):349-57.

20. Brown $\mathrm{KH}$, Jameton AL. Public health implications of urban agriculture. J Public Health Policy. 2000;21(1):20-39.

21. Warren E, Hawkesworth S, Knai C. Investigating the association between urban agriculture and food security, dietary diversity, and nutritional status: a systematic literature review. Food Policy. 2015:53:54-66.

22. Trochim WM, Cabrera DA, Milstein B, Gallagher RS, Leischow SJ. Practical challenges of systems thinking and modeling in public health. Am J Public Health. 2006;96(3):538-46.

23. Trochim WM. An introduction to concept mapping for planning and evaluation. Eval Program Plan. 1989;12:1-16.

24. Kane M, Trochim WM. Concept mapping for planning and evaluation. Thousand Oaks: Sage Publications; 2007.

25. Blay-Palmer A. Food fears: from industrial to sustainable food systems. Burlington: Ashgate Publishing Company; 2008.

26. Barthel S, Parker J, Ernstson H. Food and green space in cities: a resilience lens on gardens and urban environmental movements. Urban Stud. 2015;52(7):1321-38.
27. Vacant Lot \& Adaptive Reuse Strategy. https://www.saskatoon.ca/busin ess-development/planning/neighbourhood-planning/vacant-lot-adapt ive-reuse-strategy.

28. Frieden TR. A framework for public health action: the health impact pyramid. Am J Public Health. 2010;100(4):590-5.

29. Martin W. Urban agriculture survey. Saskatoon: University of Saskatchewan; 2017.

30. Wang D, Glicksman A. "Being grounded": benefits of gardening for older adults in low-income housing. J Hous Elder. 2013;27(1-2):89-104.

31. Kovar KA, Ball AL. Two decades of agricultural literacy research: a synthesis of the literature. J Agric Educ. 2013;54(1):167-78.

32. Powell LJ, Wittman H. Farm to school in British Columbia: mobilizing food literacy for food sovereignty. Agric Hum Values. 2018;35(1):193-206.

33. Horst M, McClintock N, Hoey L. The intersection of planning, urban agriculture, and food justice: a review of the literature. J Am Plan Assoc. 2017;83(3):277-95

34. Martin W, Vold L. Building capacity through urban agriculture: report on the askîy project. Health Promot Chronic Dis Prev Can Res Policy Pract. 2018;38(1):29.
Ready to submit your research? Choose BMC and benefit from:

- fast, convenient online submission

- thorough peer review by experienced researchers in your field

- rapid publication on acceptance

- support for research data, including large and complex data types

- gold Open Access which fosters wider collaboration and increased citations

- maximum visibility for your research: over 100M website views per year

At BMC, research is always in progress.

Learn more biomedcentral.com/submissions 